\title{
BUSINESS ENVIRONMENT, CLUSTERING, AND INDUSTRY LOCATION: EVIDENCE FROM INDIAN CITIES
}

\author{
Somik V. Lall and Taye Mengistae
}

\begin{abstract}
How do differences in the local business environment influence location of industry within countries? How do the benefits of a good business environment compare to those from good market access and agglomeration economies from industry clustering? We examine these questions by analyzing location decisions of individual firms. Using data from a recently completed survey of manufacturing firms in India, we find that both the local business environment and agglomeration economies significantly influence business location choices across cities. In particular, excessive regulation of labor and of other industrial activities reduces the probability of a business locating in a city. Our findings imply that in order to attract industrial activity, smaller or remoter cities need to offer even more attractive policy concessions or reforms in order to offset the effects of their relatively adverse (economic) geography. Our methodology pays special attention to the identification of agglomeration economies in the presence of unobserved sources of natural advantage.
\end{abstract}

Keywords: Business environment, agglomeration and clustering, firm location, Indian industry.

JEL Classification: L5, L6, R12, R3

\section{World Bank Policy Research Working Paper 3675, August 2005}

The Policy Research Working Paper Series disseminates the findings of work in progress to encourage the exchange of ideas about development issues. An objective of the series is to get the findings out quickly, even if the presentations are less than fully polished. The papers carry the names of the authors and should be cited accordingly. The findings, interpretations, and conclusions expressed in this paper are entirely those of the authors. They do not necessarily represent the view of the World Bank, its Executive Directors, or the countries they represent. Policy Research Working Papers are available online at http://econ.worldbank.org. 


\section{Introduction}

How do differences in the local business environment influence location of industry within countries? How do the benefits of a good business environment compare to benefits from good market access and agglomeration economies from industry clustering? And, can improvements in the local business environment enhance industrial activity in geographically (and historically) disadvantaged cities? Finding answers to these questions is important for assessing the role of local policies or interventions in terms of influencing investment flows and industrial activity, particularly in small and medium sized cities. To examine these questions, we start from micro-foundations by analyzing location decisions of individual firms.

We follow a modeling approach to evaluate what factors matter when a firm is considering a location to start production. Using firm level data collected in the 2003 round of the Investment Climate Survey (ICS) for India, we find that the local business environment has a significant bearing on location decisions. Predatory enforcement of business regulations reduces the probability of a business locating in a city. In comparison, better access to finance and to land and greater availability of infrastructure attract firms to a city. However, firms are also attracted by agglomeration economies from clustering of firms in their own industry. This means that new firms will choose to locate production in areas that are already established centers in their line of business. As a result cities that cannot offer the benefit of agglomeration economies to potential entrants may have to offer an even better policy environment to compensate for deficiencies in their economic geography. 
An important methodological challenge in the estimation of the location decision model is to identify the effect of local agglomeration economies in the presence of unobservable sources of "natural advantage" that could make firms locate near one another even when there are no productivity gains from clustering. ${ }^{1}$ In this case, it would not be possible to infer the presence of agglomeration economies only by looking at the number of firms of a given industry in a locality. It could be that the firms have clustered in order to reap benefits from their proximity to one another. However, it is also possible clustering could signify that these firms are drawn by a set of unobservable attributes of the locality. This endogeneity problem is particularly serious where cross section data are used in the analysis. We address this problem by using historic land revenue institutions as instruments, and find that our results on agglomeration economies are robust across model specifications. The institutions were exogenously set up during the British colonial rule, and have been found to influence agriculture investment, productivity and general district level development indicators in the post independence period [Banerjee and Iyer, 2005]. We find that differences in land revenue institutional arrangements also have implications for industrialization prospects of cities.

This paper makes several contributions to the literatures on urban and industrial development. First, there are only a handful of papers that examine location of industry within developing countries. Some of these papers have looked at the role of economic geography or agglomeration economies [Amiti and Cameron, 2004; Amiti and Javorcek, 2005; Henderson and Kuncoro, 1996; Lall and Chakravorty, 2005], but very few have

\footnotetext{
${ }^{1}$ This issue was brought into prominence in Ellison and Glaeser [1997].
} 
carefully examined the impacts of the local business environment [Deichmann et. al., 2005; Head and Reis, 1996]. ${ }^{2}$ We estimate the relative importance of agglomeration economies and the business environment using a rich set of policy relevant variables.

Second, we address the problem of identification of agglomeration economies just described. Third, the policy implications of our findings are quite significant. The finding that agglomeration economies and the local business environment jointly influence business location decisions implies that smaller or remote cities need to offer more a business friendly policy environment than more geographically advantaged locations. While geography is certainly not destiny, incremental policy reforms could be overwhelmed by adverse economic geography.

This paper proceeds in five sections. In Section II, we discuss the measurement of business environment and industrial clustering. We set out the analytic framework and discuss econometric issues in Section III. We present estimation results in Section IV. We summarize and conclude in Section V.

\section{The local business environment and agglomeration economies}

There are two broad approaches to identifying influences on firm location decisions: One is a survey-based or the "stated preference" approach, which asks decision makers what location factors are important to them. The second is a modeling approach used to identify the "revealed preference" based on site/region characteristics. Several factors, with some overlap, have been identified in the literature using these two approaches (see

\footnotetext{
${ }^{2}$ Deichmann et al. [2005] estimate the importance of both agglomeration economies and local business conditions, but their measures of business environment only capture aspects of predatory taxation.
} 
Calzonetti and Walker [1991], McCann [1998], Deichmann et. al [2005], Hanushek and Song [1978], Webber [1984]). These include

(a) "Business environment", which includes access to inputs (quality and cost of labor and capital); provision of basic infrastructure; local regulations; institutional environment; and industry-specific subsidies or tax breaks;

(b) "Agglomeration economies" from industry clustering, which include external economies provided by localization and urbanization.

In this section, we discuss both sets of factors, with particular emphasis on their relative performance across Indian cities and states. In the next section, we provide the estimation strategy to evaluate the relative importance of these factors in influencing firm location decisions.

\section{A. Business Environment}

The importance of the business environment or investment climate, as it is alternatively called, has been brought into prominence in a recent World Bank report [World Bank, 2005]. ${ }^{3}$ Based on a survey of approximately 30,000 firms across 53 developing countries this report documents the effects on economic performance from deficiencies in a country's investment climate. We complement this work by examining the impacts of deficiencies in various aspects of the business environment ${ }^{4}$ on distribution of economic activities across cities and regions within a large country. Although the term business environment includes a wide range of policies affecting the economic setting of firms, we

\footnotetext{
${ }^{3}$ The report is entitled: World Development Report 2005: A Better Investment Climate for Everyone.

${ }^{4}$ We use the terms business environment and investment climate interchangeably.
} 
narrow our focus to three aspects that show large variation across cities and regions in India and many large developing economies such as China and Brazil. ${ }^{5}$ These are: (1) Regulatory quality; (2) Provision of Infrastructure; and (3) Access to primary inputs, notably, land, labor and finance.

\section{Regulatory Quality}

In this paper we focus on two aspects of regulatory quality businesses in India face today. These are: (a) the degree of labor regulations, (b) and the intrusiveness or predatory nature of the administration of general business regulations.

Labor regulation: Excessive regulation of industrial relations is often singled out as a major drag on the international competitiveness of many of India's labor-intensive industries [World Bank 2004]. The link between industrial exit barriers and labor regulation stems from the employment security provisions of the Industrial Disputes Act of 1947. This act sets out the rules for settlement of employment termination disputes. One of its main provisions requires establishments with more than 100 workers to secure state government permission before plant closure or a retrenchment of workers; critics point out that permission is rarely granted [Sachs et al., 1999]. This has added to the protraction of insolvency procedures.

\footnotetext{
${ }^{5}$ Although issues of macroeconomic stabilization and taxation are key aspects of the business environment and are of considerable concern when the comparison is across countries, these are of lower importance when we compare investment choices within countries. We would have also liked to examine urban governance and management, but don't have reliable and comparable measures of these variables across Indian cities.
} 
The provisions of the Industrial Disputes Act have also combined with other pieces of labor legislation to inhibit the exploitation of economies of scale in industry by reducing the flexibility firms need to respond to changes in market conditions. These include the "service rules" provisions of the Industrial Employment Act of 1946 and those of the Contract Labor (Abolition and Regulation) Act of 1970. The Industrial Employment Act provides for the definition of job content, employee status, and work area by state law or by collective agreement, after which changes would not be made without getting the consent of all workers. Zagha [1999] points out that the 1946 act has always made it difficult for businesses "to shift workers not only between plants and locations, but also between different jobs in the same plant.” As a way around such restrictions, businesses may resort to contract workers, whose hiring is governed by the Contract Labor Act. This act gives state governments the right to abolish contract labor in any industry in any part of the state. In states where recourse to contract labor has been more restricted as a result, keeping employment below the threshold level of 100 employees or contracting out jobs has been the only way of maintaining flexibility in the allocation of manpower.

In our analysis, we examine how labor regulations influence location decisions of businesses, using indicators of labor regulations developed by Besley and Burgess [2004]. They examine state level amendments between 1958 and 1992 to the Industrial Disputes Act of $1947^{6}$ and code these amendments as being pro-worker, neutral, or probusiness. States with pro labor regulations have higher number of workdays lost due to

\footnotetext{
${ }^{6}$ This regulation was passed by the central government, but individual states have the right to amend it to facilitate implementation or suit it to local conditions
} 
strikes and lockouts, and they find that pro labor regulation has reduced manufacturing output per capita, and also moved economic activity from registered to unregistered manufacturing (which are not subject to labor regulations). For the purpose of the estimation, we recode pro worker regulations as 1 and neutral or pro business regulations as 0 .

Administration of general business regulations: In addition to its role in regulating business startups, business closures, and industrial relations, the government routinely comes face to face with private industry through its customs inspectors, tax officials, and those enforcing a variety of health, safety, and environmental standards that apply to all establishments employing 10 workers or more. These standards are set out in several pieces of legislation, including the Factories Act of 1948, the Water Act of 1974, the Air Act of 1981, and the Environmental Protection Act of $1986 .^{7}$ Although these are in essence federal laws, their administration is mainly the responsibility of state governments, which have considerable discretion in enforcement. ${ }^{8}$ State inspectors are the chief enforcers through their routine visits to business premises, and have the power to suspend plant operations, if necessary, for inspection purposes.

These inspections are designed to enforce many rules and regulations that are likely not much different from those implemented on a routine basis by governments in developed economies. There is, however, an important difference. In India, as in many

\footnotetext{
${ }^{7}$ More specialized standards are set in a number of statues such as the Building and Constructions Act, the Mines Safety Act, and the Child Labour Act.

${ }^{8}$ For example, the government of Tamil Nadu exempts the software producers from the provisions of the Factories Act as long as they do not engage manufacturing activities.
} 
other developing countries, individual government officers seem to have considerable discretion in deciding which rules to enforce, on whom, when, and, sometimes, how. In many cases inspection visits are arbitrary or excessive, and are viewed by business owners as punitive, or as a veiled demand for bribes. Often the latter is a price worth paying for avoiding the disruption to production plans or the loss of staff time that more frequent or more intrusive visits would otherwise bring about.

A useful proxy of the cost of imposed by predatory administration or enforcement of regulations is the frequency of visits that government officials make to business premises. On average, inspectors visit factories around 10 times each year to see if they comply with various regulations. These include taxes (sales tax, income tax, customs, and excise duty), labour and social security; fire and building safety; and environment regulations. Regulator visits, however, vary considerably across cities and states (see Figure 1). On average, firms in cities such as Delhi, Gurgaon, Chandigarh and Nagpur report less than 5 regulator visits per year. On the other hand, firms in Chennai report 17 visits, Mumbai 15, Ahmedabad 16, and Cochin 19 visits.

\section{Provision of Infrastructure}

Utilities: The investment climate survey (ICS) data show that over 30 percent of Indian firms find power supply to be the most important infrastructure bottleneck or obstacle to growth.. India's present difficulties with power supply (shortages, costs, unreliability) stem more from transmission and distribution deficiencies than from generation. In the analysis of the next section, we use the frequency of outages as our indicator of the quality 
of power supply in terms of shortages or unreliability. World Bank [2004] shows that for the average business in India, power outages occur almost every other day. In contrast, outages occur once every two weeks in China and once a week in Brazil. There is also significant variation in this indicator within India itself. On average, cities such as Surat, Ahmedabad, Nagpur, Nashik, Mumbai and Calcutta /Howrah experience less than 5 power outages each month. On the other end, cities in the North such as Jalandhar, Ludhiana (Punjab), Gurgaon and Faridabad (Haryana) and Ghaziabad and Noida (U.P) experience more than 20 outages a month.

As a result of the high frequency of power outages, the average manufacturer in India loses 8.4 percent a year in sales compared with less than 2 percent for the average manufacturer in China or Brazil. Outages can lead to loss of sales by forcing downtime (or idle capacity) on managers. They can also cause waste of materials. This happens when power disruptions cause damage to materials in process - materials that cannot be used when power and thus production resumes. Power disruptions also damage equipment, adding maintenance and repair costs that are directly attributable to the outages.

Transport: In addition to examining bottlenecks in power supply, we calculate travel times from each city to the closest port to examine if proximity to transhipment hubs and output markets influence the location decisions of manufacturing firms. In addition to the direct effects on facilitating access to markets (both national and international), transshipment nodes (such as ports) have historically been important in the evolution of urban centers. In fact, through path dependency such urban centers continue to be prosperous (and efficient) even after the initial advantage of the hub access becomes irrelevant (Fujita and Mori, 1996). 


\section{Access to inputs}

Land: Several land market distortions in Indian cities have limited firm entry and exit as well as the competitiveness of Indian industry. These include (a) unclear land ownership, (b) widespread institutional ownership of land, (c) inflexible land use and property rights, and (d) high transaction costs in the form of stamp duties. A recent report by the McKinsey Global Institute [McKinsey 2001] reports that land market distortions account for 1.3 percent of lost growth per year in India. These constraints have combined to create high land prices for businesses and households. Distortions in the land market in India have produced escalating land costs relative to per capita incomes. For example, relative land costs in New Delhi are 80 percent higher than those in Tokyo, Singapore, Jakarta, and Seoul [World Bank 2004].

About $90 \%$ of land parcels are subject to disputes over ownership, which take decades to settle in court. Subsidized user charges for water and power, low property tax rates, and ineffective tax collection leave local governments unable to recover investments in infrastructure. Inflexible land use (created by zoning difficulties and land conversion regulations) freezes land that would otherwise be available for development and affects economic entry and exit. Zoning changes involve long and cumbersome procedures resulting in pockets of "dead land." For instance, obsolete cotton mills in Mumbai and Ahmedabad dominate huge land parcels in central locations; it is neither environmentally desirable nor economically feasible to put these mills back into operation. But still the mills stand. Businesses cannot sell their assets and reinvest in other activities, and new businesses cannot build in these desirable locations. 
In the empirical analysis, we use state level stamp duty rates as an a summary indicator of such problems in access to land. Stamp duties are currently high in India, at 8$10 \%$ of the value of property changing hands. One effect they have is to reduce the supply of land on the market by discouraging land transactions. High stamp duty also provides incentives to grossly under-declare the real value of land. This in turn adversely affects the use of land as collateral for construction financing. (see Alm et. al [2004] for a discussion on the distortionary effects of stamp duties). Among states, there are considerable inter-state variations in stamp duty rates. For example, a hypothetical property valued at Rs. 1 million would be liable to pay as stamp duty Rs. 50,000 in Andhra Pradesh, Rs. 125,000 in Haryana, Rs. 38,750 in Maharashtra, and Rs. 145,000 in Uttar Pradesh.

Finance: Approximately 27 percent of firms in the ICS rate access to finance as a major to severe obstacle to business operations or growth. For the analysis in this paper, we use data on industrial credit availability, measured as the per capita lending to local industry by financial institutions. This is derived from the publication "Profiles of Districts" (CMIE), and is defined as the per capita bank credit to industries derived from the information on scheduled commercial bank branches, deposits and credits

Even during their initial phase, Indian SMEs have traditionally relied much more on debt financing — from banks and nonbank financial institutions (NBFIs) — than their counterparts elsewhere. But the shrinkage of the NBFI sector in response to policy and regulatory changes since 1997 has meant that SMEs no longer have access to finance from this source. And bank credit to SMEs has also dropped sharply since 1997. The limited debt 
financing available to Indian SMEs is of a short maturity (less than one year) and is relatively costly compared with their counterparts in other countries. ${ }^{9}$

In large part, the financing constraint faced by SMEs may be attributed to credit market imperfections, resulting in high transactions costs and default risk associated with bank lending to SMEs. Specific problems include: (a) insufficient credit information on SMEs; (b) poor SME credit-assessment practices and poor lending technologies, such as inadequate use of credit scoring/rating tools; and (c) problems in using land as collateral and nonrecognition by lenders of other types of collateral, difficulty in collateral enforcement and loan recovery, and a bankruptcy framework that prevents easy exits for troubled firms. A fourth possible contributor is the degree of confidence lenders have in courts contract enforcement mechanisms.

\section{B. Agglomeration Economies}

Agglomeration economies are production related externalities that directly affect the firm's microeconomic decision making. Most fundamentally, clusters of firms that are predominantly in the same sector take advantage of so-called localization economies. They include sharing of sector specific inputs, skilled labor and knowledge, intra-industry linkages, and opportunities for efficient subcontracting. Marshall-Arrow-Romer [Marshall 1890, Romer 1986] externalities suggest that cost-saving externalities are maximized when a local industry is specialized. These models predict that these

\footnotetext{
${ }^{9}$ An alternative indicator of the ease of access to formal sector external finance is the proportion of small businesses that have active bank credit lines or overdraft facilities -- approximately 54 percent of small businesses in the India ICS sample belong to this group. This is much higher relative to China but lower than Brazil's by about 50 percent.
} 
externalities predominantly occur within the same industry. Therefore, if an industry is subject to such externalities, firms are likely to locate in a few regions where other producers of that industry are already clustered.

At the next level, inter-industry linkages in the form of buyer-supplier relationships may complement intra-industry externality effects. Empirically, the distinction between own-industry versus cross-industry linkages depends on the level of sectoral aggregation. At the two-digit industry code level, many activities are considered internal to the sector that would be classified as cross-sectoral using a three-digit classification. So at high sectoral aggregation, an input-output table, which summarizes buyer-supplier linkages between sectors, will show flows of goods as diagonal table elements, which would be off-diagonal inter-industry interactions in a less aggregated sectoral classification. Venables [1996] shows that agglomeration can occur through the combination of firm location decisions and buyer-supplier linkages even without high factor mobility. For an industry heavily dependent on intermediate goods and services as inputs to production, access to suppliers lowers transaction costs and increases profitability. Inter-industry linkages can also serve as a channel for vital information transfers. Firms that are linked through stable buyer-supplier chains exchange ideas on how to improve the quality of their products or on how to realize cost savings. It is such on-going interaction that makes the dynamics of inter-industry externalities so vibrant and reinforces the localization process. ${ }^{10}$

\footnotetext{
${ }^{10}$ At a third level, a larger overall size of the urban agglomeration and its more diverse industry mix is thought to provide external benefits beyond those realized within a single sector or a tight buyer-supplier network (Henderson 2003). These benefits are typically called urbanization economies. Larger cities have a greater diversity of firms. This allows greater specialization since it enables small, innovative firms to
} 


\section{Own industry concentration}

Several different metrics of localization have been employed by agglomeration studies including single industry employment in a region, same industry establishments in a region, or an index of concentration that indicates disproportionate specialization of the region in the industry when compared to the nation. Measures such as single industry employment and the location quotient, an indicator of specialization, have been commonly used in empirical studies, but are problematic because they do not account for local differences in the industry's firm-size distribution. Single industry employment in a particular region may be due to common location of several similar firms or a single firm with many workers and the conventional measures treat both circumstances equally. Localization economies require interaction between firms so a more appropriate measure should recognize the importance of the number of firms in addition to the number of workers in an industry because both these factors affect the scope and scale of interaction.

For the analysis in this paper, we develop a measure of own industry concentration that adjusts industry employment in each region for the industry's local firm-size distribution. This measure $\widetilde{\mathrm{e}}_{\mathrm{ri}}$ is firm-size adjusted employment for industry $i$ in city $r$, and is defined as:

access a larger pool of potential buyers and complementary services that cannot be provided in-house. Larger cities also provide a larger home market for end products, make it easier to attract skilled employees who are attracted by urban amenities not available in smaller towns, and support a large number of complementary service providers such as financial and legal advisers, advertising and real estate services. Manufacturing firms will also require complementary services such as legal, financial and other advisory services. These are likely to be available in larger, more diverse urban areas. 


$$
\tilde{e}_{r i}=e_{r i}\left(1-h_{r i}\right)
$$

where $h_{r i}=\sum_{j=1}^{n} z_{i j}^{2}$ is the Herfindahl index for industry $i$ in region $r$ and is calculated as the sum of squared firm shares of local industry employment and $e_{r i}$ is industry i's employment in city $r$. Multiplying raw industry employment by $\left(1-h_{r i}\right)$ has the desired effect of penalizing regions that have "lumpy" industry employment, that is, few firms with many workers.

To illustrate the importance of controlling for firm-size distribution in the measurement of localization potential, let us consider the following two-region example. Total single industry employment in Region 1 is 200 , distributed evenly across 10 firms. In this case, the Herfindahl index is 0.1 and adjusted employment $\widetilde{\mathrm{e}}_{1 \mathrm{i}}$ is 180 . The adjusted employment showing localization potential is nearly the same as pure employment, reflecting the considerable possibility for firm interaction. In comparison, total industry employment in Region 2 is also 200, but distributed between two firms, with the first firm having 180 employees and the other firm with 20 employees. In this case, the Herfindahl is 0.82 , and the adjusted employment $\widetilde{\mathrm{e}}_{2 \mathrm{i}}$ is 36 . This example shows that a fewer number of firms and 'lumpy' employment in one firm reduces the overall potential for localization economies. Thus, our measure $\widetilde{\mathrm{e}}_{\mathrm{ri}}$ penalizes regions where employment is concentrated in a few firms. For the analysis, we calculate own industry concentration using employment and firm-size distribution statistics provided in the 1998-99 sampling frame of the ASI, which provides employment data on the universe of registered industrial establishments in India. 


\section{Estimation Framework}

The objective of the empirical analysis is to evaluate the relative importance of the business environment and agglomeration economies in influencing location decisions of manufacturing firms across Indian cities. Here, we provide an estimation framework, where individual firms compare potential profitability across cities in India. We assume that a firm evaluates potential profits at alternative locations at each time period, and would consider relocation if profits in another place exceeded its profits at the current location. By viewing past location decisions as being under constant review by firms, this framework allows us to investigate what location benefits are embedded in the firm's current production technology.

\section{A. Estimation Framework}

The units of observation in our analysis are all firms covered in the Investment Climate Survey. The underlying location decision model for each firm determines profits as a function of observable attributes of the business environment and agglomeration economies, and a set of unobserved local attributes of the city. In the model profits $\pi$ earned by firm $i$, in industry $k$, which chooses to locate in city $j$ are: ${ }^{11}$

$$
\pi_{i, j, k}=f\left(\sigma_{j, k}, R_{j}, I N_{j}, A_{j}, W_{j}, \eta_{i, j, k} ; \bar{\beta}_{k}\right)
$$

Agglomeration effects that provide production externalities are represented by $\sigma_{j, k}$ (localization economies), measured as the own industry concentration of industry $i$ in city

\footnotetext{
${ }^{11}$ This model is an adaptation of the Bayer and Timmis [2003] equilibrium model of location choice to the problem of industrial development.
} 
$j$, as described in equation (1). $R_{j}$ measures regulatory quality, various aspects of the business environment, $I N_{j}$ represents the quality and availability of infrastructure; and $A_{j}$ represents access to inputs such as industrial finance and land. These three sets of variables represent the local business environment. $W_{j}$ represents labor costs (manufacturing wages) in city $j$.

We choose the following functional form for this profit function:

(3) $\pi_{i, j, k}=\beta_{0, k}+\beta_{\sigma, k} \sigma_{j, k}+\beta_{R, k} R_{j}+\beta_{I N, k} I N_{j}+\beta_{A, k} A_{j}+\beta_{W, k} W_{j}+\eta_{i, j, k}$

The ith firm will choose city $j$ if $\pi_{j}^{i} \geq \pi_{l}^{i}$ for all $l$, where $l$ indexes all the possible city choices to $i$ th firm. For estimation we will assume that $\eta_{i, j}$ is additively separable from the rest of the utility function, and has a Weibull distribution. The result is that we can write the probability that any firm will choose to locate in city $j$ [McFadden, 1973]:

$$
P\left(\pi_{i, j} \geq \pi_{i, l} \forall I \neq j\right)=\frac{e^{\beta_{0, j}+\beta_{\sigma, k} \sigma_{j, k}+\beta_{R, k} R_{j}+\beta_{I N, k} I N_{j}+\beta_{A, k} A_{j}+\beta_{W, k} W_{j}}}{\sum_{m=1}^{J} e^{\beta_{0, m}+\beta_{\sigma, k} \sigma_{m}+\beta_{R, k} R_{m}+\beta_{I N, k} I N_{m}+\beta_{A, k} A_{m}+\beta_{W, k} W_{m}}}
$$

In our estimation, we are assuming that each firm takes attributes associated with each city as given and make rational location choice decisions. For the purpose of estimation this assumption translates into a condition where the idiosyncratic error term is independent of the city characteristics. 
We make one addition to the specification in equation 3 . The $\beta_{j}$ 's for $j \in\{\sigma, R, I N, A, W\}$ in equation 3 are the parameters of the profit function with respect to each of these characteristics. We believe, however, that firms with multiple establishments value location based amenities differently relative to single establishment firms [Baldwin 1995, 1998]. For instance, factories or establishments belonging to a multi establishment firm may be able to source intermediates from their sibling establishments, and thereby rely less on horizontal linkages with other firms. Similarly, larger firms may be able to afford specialized services of lawyers who can handle regulatory problems for multiple establishments. However, the extent to which this makes a difference is an empirical question. Therefore in our analysis, we allow each firm's valuation of the choice set to vary with its status of being a single establishment entity or a branch plant. Including this component of the profit function that varies between branch plants and independent establishments:

$$
\pi_{i, j, k}=\theta_{j, k}+\sum_{r=1}^{R} \beta_{r j} Z_{r}^{i}+\eta_{i, j, k}
$$

We estimate the model in two stages. First, we construct a set of industry-specific likelihood functions based on equations (4) and (5), and estimate a conditional logit model to recover estimates of $\bar{\theta}_{j, k}, k=1,2, \ldots, K$. In the second stage, we take the estimated value of the choice specific constant or city specific premium, $\hat{\theta}_{j, k}$, and estimate the following regression: 


$$
\hat{\theta}_{j, k}=\beta_{0, k}+\beta_{\sigma} \sigma_{j, k}+\beta_{R, k} R_{j}+\beta_{I N, k} I N_{j}+\beta_{A, k} A_{j}+\beta_{W, k} W_{j}
$$

We organize industries into four types $(k \mathrm{~s})$, based on a classification developed in Lall [1999]. At one end of the spectrum are what resource based industries, involving primary processing of agricultural products and natural resources. This sector includes the food and tobacco industries, wood processing, tanneries, and precious stones. Although most industries in this sector are relatively labor intensive, their distinguishing characteristic in the context of trade is that the competitiveness of a locality or a country in their production stems from the availability of specific natural resources. Relatively labor intensive, low-entry barrier industries in which competitiveness depends more on the relative price of unskilled labor than on the cost of raw materials constitute low tech industries, including textiles, garments, leather goods, furniture and fabricated metal products. Then there are the medium or high technology industries that are as a rule more capital and skill intensive and, more importantly, are characterized significant to large $\mathrm{R}$ \& D expenditure that also make entry costs concomitantly higher. Our grouping of industries based on this classification is provided in Appendix 2.

\section{Identification of agglomeration economies}

We just described a model of firm location choice, where a firm chooses a location for production based on its valuation of the local business environment and agglomeration economies derived from own industry concentration. The choice of variables described in Section II is derived from theoretical priors and various empirical studies. However, in addition to these observed attributes, it is possible that firms also 
optimize their decision based on a set of unobserved attributes, i.e those that are considered by the entrepreneur but not observed in the data. In the presence of these unobservable attributes, Equation (6) is modified as follows:

$$
\hat{\theta}_{j, k}=\beta_{0, k}+\beta_{\sigma} \sigma_{j, k}+\beta_{R, k} R_{j}+\beta_{I N, k} I N_{j}+\beta_{A, k} A_{j}+\beta_{W, k} W_{j}+\xi_{j, k}
$$

Where $\xi_{j, k}$ represents unobserved characteristics of the city that influences a firm's location choice. Presence of these unobservable local attributes complicates the estimation procedure, particularly in identifying the contribution of production externalities to the location decisions of firms. Ellison and Glaeser [1997] point out that the effects of unobservable sources of "natural advantage" (i.e., positive values of $\xi_{\mathrm{j}, \mathrm{k}}$ ) will not be separately identified from those of production externalities between firms that arise simply from firms locating near one another. Simply including the number of firms or employment in a particular industry, which is a commonly used indicator in empirical studies evaluating localization economies, will not allow us to distinguish whether firms are attracted by a common unobservable, whether they derive benefits from being located in close proximity to one another, or whether it is some combination of the two.

If we had access to panel data, we would have been able to difference out the effects of unobservables, ${ }^{12}$ and then get unbiased estimates of own industry clustering. With cross section data, we need to find instruments that are good predictors of current industry concentration, but not correlated with unobservable sources of natural advantage. Often used instruments such as deeply lagged values of industry concentration

\footnotetext{
${ }^{12}$ We are assuming that these unobservable attributes don't change over time.
} 
are not satisfactory for this purpose. For example, unobserved factors that influenced industry location decisions 30 years ago could still matter for industry location decisions today.

In our quest for appropriate instruments we examine if exogenously established historical institutions set into place a process of path dependence that has implications for present day industrial development. For this, we draw on Banerjee and Iyer's [2005] research on colonial land tenure and revenue systems in India, where they study the different land revenue systems instituted through the British colonial rule of India during the early nineteenth century, and examine its impact on a variety of present day economic and social indicators. Land revenue was the most important source of government revenue, and the British instituted three systems defining who was responsible for paying the land taxes. These were (a) landlord based systems (zamindari or malguzari), individual cultivator-based systems (raiyatwari) or village-based systems (mahalwari). ${ }^{13}$

Banerjee and Iyer (2005) find that post independence agricultural investments and productivity were lower in districts where land rights were given to landlords compared to districts were rights were given to cultivators. They show the effects of 'institutional overhang' on economic performance because while these land revenue institutions established during the British colonial rule ended with Indian independence, their effects are observed much later in history.

\footnotetext{
${ }^{13}$ In landlord-based systems, the landlord was responsible for collecting revenues from a number of villages after retaining part of the revenue he collected; in individual-based systems British government officers collected revenue directly from cultivators; and in village-based systems, a village community body bore the responsibility for revenue collection.
} 
Banerjee and Iyer's (2005) study of historic land tenure institutions and agricultural performance is of interest to our analysis for three reasons. First, the British decision on which land tenure system to adopt depended more on the preferences of individual administrators rather than a systematic evaluation of region specific characteristics. ${ }^{14}$ Thus the choice of institutional arrangement is largely exogenous to regional attributes. Second, landlords were allowed to extract as much as they wanted from their tenants, thus making their behavior predatory, leading to high inequality and low general investment in their districts. Further, as most wealthy landlords were not cultivators themselves, this reduced pressure on the state to deliver services important to farmers as well as general public goods. The consequences of this system are observed in terms of lower education and health infrastructure and outcomes. Third, rural institutions have considerable bearing on urban and industrial development (Rao and Woolcock 2001). Rural class structures and social networks do not disappear once people move to cities. In fact, rural or origin based identities are even stronger as people sort themselves into homogenous groups within heterogeneous settings.

We link Banerjee and Iyer's (2005) land revenue classification with the 1991 district boundaries using geographic information system (GIS) based matching. For the analysis, we use the land revenue system of the district where the city is located and assign that value to the city. We then identify the cities whose districts had landlord based/ zamindari systems and recode these as 1 and code other cities with a 0 . Thus, we end up with a binary measure of landlord control. To examine if there is any association

\footnotetext{
${ }^{14}$ Banerjee and Iyer note that these decisions were often based on not much more than instincts of administrators.
} 
between landlord control and industry employment, we compare average (firm size adjusted) industry employment in our three industry categories in landlord and nonlandlord districts (Table 3). We find significantly lower levels of industry concentration in landlord districts for all industry types. This suggests that the differences between these two categories is not simply an industry composition effect, but truly reflects lower levels of industrial activity in landlord districts. We also ran OLS estimations and find that having a historic landlord based land revenue system is negatively associated with industry concentration.

\section{Results}

\section{A. Data}

To estimate the models set out in the preceding section, we have combined industry survey data from the World Bank's Investment Climate Survey (ICS) of India along with establishment level data from the Annual Survey of Industries (ASI). ${ }^{15}$ The ICS survey was conducted from March to July 2003 on a random selection of 1,860 manufacturing establishments sampled from 40 cities in 12 of India's 14 major states. ${ }^{16}$ A list of cities covered in the ICS is provided in Appendix 1. These cities are representative of the main industrial centers in the country as each state is represented by its top 3 or 4 industrial cities accounting for the bulk of its manufacturing Gross State Domestic Product (GSDP). These 12 states themselves account for $94 \%$ of India's

\footnotetext{
${ }^{15}$ The World Bank and the Confederation of Indian Industry (CII) have jointly carried out the ICS, and the Indian Central Statistical Office annually carries out the ASI. The ASI covers factories registered under sections $2 \mathrm{~m}$ (i) and $2 \mathrm{~m}$ (ii) of the Factories Act 1948, employing 10 or more workers and using power, and those employing 20 or more workers but not using power on any day of the preceding 12 months.

${ }^{16}$ These are Andhra Pradesh, Delhi, Gujarat, Haryana, Kerala, Karnataka, Madhya Pradesh, Mahrashtra, Punjab, Tamil Nadu, Uttar Pradesh, and West Bengal.
} 
Industrial GDP. Based on shares in aggregate sectoral output, the sample was largely drawn from eight manufacturing sectors: garments, textiles, leather, drugs and pharmaceutical, electronic goods and equipment, electrical white goods, auto parts, and food processing.

To complement the ICS data, we use employment statistics provided in the 199899 sampling frame of the ASI, which provides employment data on the universe of registered industrial establishments in India. We aggregate plant level employment to create measures of agglomeration economies. Table 1 lists the variables used in our empirical estimation along with their sources and summary statistics.

\section{B. Factors Influencing Firm Location Decisions}

We first estimate Equation (5) to recover industry specific city premiums and also the estimates of differences in valuation between branch plants and single establishment firms. We do not report the industry-city specific premiums here, but these are available on request. Let us first examine if multi establishment firms value location-based attributes any differently from single establishment firms. These results are reported in Table 2. These coefficients are difficult to interpret as they indicate the preference of multi establishment firms for characteristics of a city relative to single establishment firms. Interactions between multi establishment firms and city characteristics for all industry types are jointly significant. However, only few of the estimated coefficients are individually significant. There are two variables where multi-establishment firms across industry types are more sensitive to the local business environment. These are proximity to an international port and effective stamp duty rates. 
Now, let us turn to interpreting results from estimating Equation (6), which explains variations in city-industry specific premiums. Estimated coefficients are provided Table 3 . We have organized the findings around the relative importance of the business environment and agglomeration economies/ clustering. Columns 1, 2, and 3 in Table 4 provide results for low, medium and high technology manufacturing firms respectively.

\section{Business Environment}

Labor regulations: We find that across industries, the coefficient for labor regulation is negative and significant, which implies that cities located in states that have passed pro labor regulations have lower attractiveness in terms of location decisions of manufacturing firms. These effects are stronger for high technology manufacturing. Our findings are consistent with those from Dollar, Iarossi and Mengistae (2002), who survey 1000 manufacturing establishments from 10 Indian states and find that that managers would be willing to reduce their work force by $16-17$ percent if there was greater labor market flexibility, indicating the negative impact of labor regulation on firm productivity. The negative impact of labor regulations on formal sector manufacturing is also seen in cross-country evidence. For example, Botero et. al. (2004) study labor regulations in 85 countries and find that heavier regulation of labor is associated with a larger unofficial economy. 
Enforcement of business regulations: In terms of predatory enforcement of business regulations, we find that the frequency of visits by inspectors to plants in each city has a significant negative effect on the attractiveness of a city for investment in all broad sectors. As both city attractiveness $(\hat{\theta})$ and inspector visits are in logs, the estimated coefficients can be interpreted as elasticities. For example, in low technology firms, the coefficient of -0.66 means that a 10 percent increase in the frequency of inspection visits reduces a city's investment attractiveness by 6.6 percent. The effects are relatively stronger for high technology manufacturing.

Utilities: We find that the frequency of power outages has a significant negative effect on a city's investment attractiveness. This finding is consistent for all industry types, and stronger for high technology manufacturing. For these firms, the coefficient of -0.29 means that a 10 percent increase in the frequency of power outages reduces a city's investment attractiveness by 2.9 percent. The negative impact of utility failures is consistent with Mani et. al. [1997], who also find negative effects of state level power shortages and of energy prices on industry location decisions in India.

Transport (Access to external markets): Locating in a region with good access to markets is likely to increase demand for the firm's products. We find that port distance significantly influences location decisions of firms across industry categories. For example, in medium technology manufacturing, the coefficient of -0.19 means that a 10 percent reduction in distance to the nearest international port will be associated with an approximately 1.9 percent increase in the city's attractiveness or potential profitability. 
Thus, all other things being equal, coastal cities that have international port facilities are likely to attract a larger share of investment.

Access to land: We used variations in stamp duty rates to examine the implications of problems in access to land on firm location decisions. Our results show that the effective stamp duty rate has a significant negative effect on location choices in all industry types.

Access to finance: We find that access to finance has a significant positive effect on location decisions. In medium technology manufacturing, the coefficient of 0.06 means that a 10 percent reduction in distance to the nearest international port will be associated with an approximately 0.6 percent increase in the city's attractiveness. The results are relatively lower for high and low technology manufacturing.

Factor prices: Our prior expectations are that the level of wages should have a negative impact on economic activity, once other factors are conditioned out. The findings from our analysis are quite mixed. We find that cross city variations in wages have strongly negative effects on activity in high technology sectors, no effect in medium technology sectors, and a positive effect on low technology sectors. ${ }^{17}$ A possible reason for this ambiguity of the effect of high wages is the difficulty in controlling for the skill composition of each firm's labor force.

\footnotetext{
${ }^{17}$ For Indonesia the effects are similarly mixed (Henderson and Kuncoro 1996, Deichmann et al 2005).
} 


\section{Agglomeration Economies/ clustering effects}

For estimating Equation (6), we used the own industry concentration measure specified in Equation (1), which is the firm-size adjusted employment for each industry city pair. The estimated parameters are statistically significant and positive for all broad sectors under examination. This suggests that, at this level of industrial and geographic aggregation, own-industry concentration or localization economies have a considerable impact on location decisions of firms. The results for low technology industries show that a 10 percent increase in own industry concentration will increase city's attractiveness by 1.1 percent (or a doubling of own industry concentration increases investment attractiveness by 11 percent). The estimated effects are higher for medium (18 percent) and high (33 percent) technology firms.

Next, we estimate Equation (7) using IV techniques, and instrument own industry concentration with the choice of land revenue system. We performed the Durbin-WuHausman test to examine if endogeneity of own industry concentration would have adverse effects on OLS estimates. The test results reject the null hypothesis that industry concentration is exogenous, suggesting that IV estimates would be preferable to those from OLS. ${ }^{18}$ While the binary variable is a crude measure, it still is a good predictor of industry concentration, and not associated with unobserved sources of natural advantage. Results from these estimations are reported in Table 5. We have also included the OLS estimates from Table 4 for reference. We find that own industry concentration is still a significant and positive determinant of firm location decisions, as reflected in the city-

\footnotetext{
${ }^{18}$ Test results are provided in Table 5.
} 
industry attractiveness index. For low and medium technology firms, the IV estimates are in fact larger in magnitude that the OLS estimates, which suggests that any endogeneity present has a small effect. For high technology manufacturing however, the IV estimate is 0.17 , which is almost half in magnitude of the coefficient estimated with OLS. Thus, we find that own industry clustering has a significant impact on firm location decisions even after we take into account potential endogeneity problems in identifying the effects of industry clustering / agglomeration economies.

\section{Conclusion}

In this paper, we examine the relative importance of the local business environment and agglomeration economies on location decisions of manufacturing firms in India. We disaggregate the business environment into (a) regulatory quality, (b) infrastructure quality; and (c) access to inputs such as finance and labor. We estimate a location choice model where a firm optimizes its location decision across Indian cities based on a set of observable business environment and agglomeration variables. We use

firm level data from the Indian Investment Climate Survey (ICS) for India and find that the local business environment has a significant bearing on location decisions. Predatory enforcement of business regulations and excessive labor regulations have adverse effects on location decisions, while availability of infrastructure and access to finance and land have positive impacts.

However, agglomeration economies from own industry clustering also positively influence firm location decisions. This means that new firms will choose to locate 
production in areas that are already established centers in their line of business. An important methodological challenge in the estimation of these types of location decision models is to separately identify the effects of local agglomeration economies from those of unobservable sources of "natural advantage" simply by observing many firms locating near one another. To address this concern, we use exogenously instituted land revenue institutions set up during the British colonial rule as an instrument to predict industry concentration. We find existence of considerable institutional overhang, where historic institutions have bearing on current day industry concentration. Further, the impacts of agglomeration economies are significant even after addressing endogeneity concerns.

Finally, the implications of our findings are quite relevant for local policy initiative designed to attract industry in small and medium sized cities. As both agglomeration economies from clustering and the local business environment jointly influence business location decisions, smaller or remote cities need to exert relatively higher effort in terms of policy reforms to offset costs imposed by adverse geography. 


\section{References}

Amiti, Mary and Beata. Smarzynska Javorcik (2005), "Trade Costs and Location of Foreign Firms in China", mimeo, World Bank, Washington DC.

Amiti, Mary and Lisa Cameron (2004), "Economic Geography and Wages", CEPR Discussion Paper, 4234.

Alm, Jim, Patricia. Annez, and A. Modi (2004). "Stamp duties in Indian states - a case for reform." World Bank Policy Research Working Paper, 3413.

Baldwin, J.R. (1995). The Dynamics of Industrial Competition. New York: Cambridge University Press.

Baldwin, J.R. (1998). "Were Small Firms the Engines of Growth in the 1980s?" Small Business Economics 10: 349-64.

Banerjee, Abhijit and Lakshmi Iyer (2005). History, Institutions and Economic Performance: The Legacy of Colonial Land Tenure Systems in India. American Economic Review.

Bayer, Patrick and Christopher Timmins (2003). "Estimating Equilibrium Models of Sorting Across Locations," Yale Economic Growth Center Working Paper 862,

Besley, Timothy and Robin Burgess (2004) "Can labor regulation hinder economic performance? Evidence from India”, The Quarterly Journal of Economics 119(1), 91-134, February.

Botero, J., Simeon Djankov; Rafael Porta; Florencio C. Lopez-De-Silanes (2004). The Regulation of Labor, The Quarterly Journal of Economics, November, 119, 4, 13391382(44).

Calzonetti, F. J. and R. T. Walker. (1991). Factors Affecting Industrial Location Decisions: A Survey Approach. In Industry Location and Public Policy. Editors H. W. Herzog and A. M. Schlottmann. The University of Tennessee Press, Knoxville.

Deichmann, Uwe, Kai Kaiser, Somik V. Lall, and Zmarak Shalizi (2005), "Agglomeration, Transport and Regional Development in Indonesia", World Bank Policy Research Working Paper, 3477.

Dollar, David., I. Giuseppe, and Taye Mengistae, (2002), "Investment Climate and Economic Performance: Some Firm Level Evidence from India” Working Paper No. 143, Center for Economic Research and Policy Reform, Stanford University.

Ellison, Glenn and Edward Glaeser (1997), Geographic concentration in US manufacturing industries: A dartboard approach, Journal of Political Economy 105(5):889-927.

Fujita, Masa and T. Mori (1996), The role of ports in the making of major cities: Selfagglomeration and hub-effect. Journal of Development Economics, 49. 93-120.

Hanushek, E. A., and B. N. Song. 1978. The Dynamics of Postwar Industrial Location. The Review of Economics and Statistics 60: 515-22 
Head, K., and J. Ries (1996), "Inter-City Competition for Foreign Investment: Static And Dynamic Effects of China's Incentive Areas", Journal of Urban Economics, 40(1), 38-60.

Henderson, Vernon, Ari Kuncoro and M. Turner (1995), "Industrial development in cities. Journal of Political Economy", 103, 1067-1090.

Henderson, Vernon, 2003, The urbanization process and economic growth: The so-what question? Journal of Economic Growth 8, 47-71

Lall, Somik V., Zmarak Shalizi and Uwe Deichmann. (2004). "Agglomeration Economies and Productivity in Indian Industry." Journal of Development Economics, 73, 2, 643-673, 2004.

Lall, Somik V. and Sanjoy Chakravorty (2005), "Industrial Location and Spatial Inequality: Theory and Evidence from India". Review of Development Economics, 9, 47-68, 2005.

Lall, Sanjaya (1999). India's Manufactured Exports: Comparative Structure and Prospects. World Development, vol.27, no. 10, pp. 1769-1786.

McFadden, D. (1973). "Conditional Logit Analysis of Qualitative Choice Behavior." in P. Zarembka, ed., Frontiers in Econometrics. New York: Academic Press.

McKinsey (2001), India: The Growth Imperative. McKinsey Global Institute. http://www.mckinsey.com/mgi/publications/india.asp

Mani Muthukumara, Sheoli Pargal and Mainul Huq (1997), 'Does environmental regulation matter? Determinants of the location of new manufacturing plants in India in 1994', The World Bank, Policy Research Working Paper, \#1718.

Marshall, Alfred. (1890). Principles of Economics. London: Macmillan.

McCann, Peter (1998), The Economics of Industrial Location: A Logistics-Costs Approach. Springer, New York.

Rao, Vijayendra and Michael Woolcock (2001). "Social Networks and Risk Management Strategies in Poor Urban Communities: What Do We Know?" mimeo. Available online: http://poverty.worldbank.org/files/11983 WDRNetworksNote.doc

Romer, Paul M., 1986, Increasing returns and long-run growth, Journal of Political Economy 94 (5), 1002-37, October.

Sachs, Jeff, Ashutosh Varshney, and Nirupam Bajpai (eds) (1999). India in the Era of Economic Reforms. New Delhi: Oxford University Press

Timmins, Christopher (2005) Estimable equilibrium models of locational sorting and their role in development economics, Journal of Economic Geography.

Venables, Anthony J., 1996, Equilibrium locations of vertically linked industries, International Economic Review 49, 341-359.

Webber, M. J. 1984. Industrial Location. Sage, Beverly Hills, CA. 
World Bank (2004). "India: Investment Climate Assessment 2004 - Improving Manufacturing Competitiveness.” World Bank. Washington and New Delhi. November 2004.

World Bank (2005). World Development Report: A Better Investment Climate For Everyone

Zagha, Roberto (1999). "Labor and India's Economic Reforms." In Sachs et al. (eds), India in the Era of Economic Reforms. New Delhi: Oxford University Press. 
Table 1: Summary Statistics

\begin{tabular}{llcc}
\hline Variable & Source & Mean & Std. Dev. \\
\hline \hline Pro labor regulation =1; 0 otherwise & Besley and Burgess (2004) & 0.263 & 0.440 \\
(In) inspector visits & ICS & 2.257 & 0.489 \\
(In) power outages & ICS & 2.184 & 1.143 \\
(In) distance to international port & Lall et. al (2004) & 1.961 & 1.081 \\
Stamp duty rate & World Bank (2004) & 7.984 & 3.483 \\
(In) industrial credit & CMIE & 7.056 & 1.617 \\
(In) wages & ASI & 10.566 & 0.371 \\
(In) own industry concentration (low technology) & ASI & 9.616 & 1.418 \\
(In) own industry concentration (medium technology) & ASI & 8.605 & 1.515 \\
(In) own industry concentration (high technology) & ASI & 7.852 & 1.556 \\
Zamindari land revenue system -1; 0 otherwise & Banerjee and lyer (2005) & 0.158 & 0.365 \\
\hline
\end{tabular}


Table 2: Parameter estimates on interactions in conditional logit

\begin{tabular}{lccc}
\hline Multiple establishment firm X City & Low & $\begin{array}{c}\text { Medium } \\
\text { Characteristic }\end{array}$ & $\begin{array}{c}\text { High } \\
\text { Technology }\end{array}$ \\
\hline Pro labor regulation & -0.63 & -0.18 & -0.58 \\
& {$[0.36]+$} & {$[0.38]$} & {$[0.43]$} \\
(In) inspector visits & 1.14 & 0.41 & 0.33 \\
& {$[0.34]^{\star *}$} & {$[0.38]$} & {$[0.41]$} \\
(In) power outages & -0.04 & 0.16 & -0.08 \\
& {$[0.13]$} & {$[0.13]$} & {$[0.16]$} \\
(In) distance to international port & -0.21 & -0.24 & -0.23 \\
& {$[0.12]+$} & {$[0.14]+$} & {$[0.14]+$} \\
stamp duty rate & -0.07 & -0.06 & -0.08 \\
& {$[0.04]+$} & {$[0.04]+$} & {$[0.06]$} \\
(In) industrial credit & -0.03 & -0.06 & 0.33 \\
& {$[0.08]$} & {$[0.07]$} & {$[0.12]^{\star *}$} \\
(In) wages & -0.41 & -0.15 & 0.71 \\
& {$[0.40]$} & {$[0.51]$} & {$[0.63]$} \\
(In) own industry concentration & 0.03 & -0.04 & -0.2 \\
& {$[0.08]$} & {$[0.10]$} & {$[0.14]$} \\
Observations & 26011 & 22496 & 14467 \\
\hline \multirow{2}{*}{$\chi^{2}$ tests of joint significance } & & & \\
\end{tabular}

Standard errors in brackets

+ significant at 10\%; * significant at 5\%; ** significant at $1 \%$ 
Table 3: Industry concentration differences between landlord and other land revenue systems

\begin{tabular}{llll}
\hline Revenue System & Low Technology & Medium Technology & High Technology \\
\hline $\begin{array}{l}\text { Landlord/ zamindari } \\
\text { system }\end{array}$ & 20217 & 3898 & 1826 \\
$\begin{array}{l}\text { Other land revenue } \\
\text { systems }\end{array}$ & 38771 & 15293 & 8378 \\
\hline
\end{tabular}

Note: Numbers in cells are firm size adjusted employment figures (see Equation (1) for specification of own industry concentration).

Table 4: Factors influencing industry location (city attractiveness)

\begin{tabular}{lccc}
\hline & Low & Medium & High \\
City Attractiveness & Technology & Technology & Technology \\
\hline \hline Pro labor regulation & -0.45 & -0.43 & -0.68 \\
& {$[0.01]^{\star \star}$} & {$[0.01]^{\star \star}$} & {$[0.02]^{\star \star}$} \\
(In) inspector visits & -0.66 & -0.64 & -0.8 \\
& {$[0.01]^{\star \star}$} & {$[0.01]^{\star \star}$} & {$[0.01]^{\star \star}$} \\
(In) power outages & -0.13 & -0.15 & -0.29 \\
& {$[0.00]^{\star \star}$} & {$[0.00]^{\star \star}$} & {$[0.01]^{\star \star}$} \\
(In) distance to international port & -0.13 & -0.19 & -0.46 \\
& {$[0.00]^{\star \star}$} & {$[0.00]^{\star \star}$} & {$[0.01]^{\star \star}$} \\
stamp duty rate & -0.03 & -0.03 & -0.05 \\
& {$[0.00]^{\star \star}$} & {$[0.00]^{\star \star}$} & {$[0.00]^{\star \star}$} \\
(In) industrial credit & 0.03 & 0.06 & 0.01 \\
& {$[0.00]^{\star \star}$} & {$[0.00]^{\star \star}$} & {$[0.00]^{\star \star}$} \\
(In) wages & 0.25 & 0.01 & -0.14 \\
& {$[0.01]^{\star \star}$} & {$[0.01]$} & {$[0.03]^{\star \star}$} \\
(In) own industry concentration & 0.12 & 0.18 & 0.34 \\
& {$[0.01]^{\star \star}$} & {$[0.01]^{\star \star}$} & {$[0.01]^{\star \star}$} \\
Constant & 1.87 & 6.51 & 5.77 \\
& {$[0.07]^{\star \star}$} & {$[0.10]^{\star \star}$} & {$[0.25]^{\star \star}$} \\
\hline R-squared & 0.52 & 0.47 & 0.48 \\
\hline Robus
\end{tabular}

Robust standard errors in brackets

+ significant at 10\%; * significant at 5\%; ** significant at $1 \%$ 
Table 5: Factors influencing industry location - IV estimates

\begin{tabular}{|c|c|c|c|c|c|c|}
\hline & \multicolumn{2}{|c|}{ Low Technology } & \multicolumn{2}{|c|}{ Medium Technology } & \multicolumn{2}{|c|}{ High Technology } \\
\hline & OLS & IV & OLS & IV & OLS & IV \\
\hline \multirow[t]{2}{*}{ Pro labor regulation } & -0.45 & -0.51 & -0.43 & -0.39 & -0.68 & -0.75 \\
\hline & {$[0.01]^{\star \star}$} & {$[0.01]^{\star \star}$} & {$[0.01]^{\star \star}$} & {$[0.01]^{\star \star}$} & {$[0.02]^{\star \star}$} & {$[0.02]^{\star \star}$} \\
\hline \multirow[t]{2}{*}{ (In) inspector visits } & -0.66 & -0.67 & -0.64 & -0.63 & -0.8 & -0.82 \\
\hline & {$[0.01]^{\star \star}$} & {$[0.01]^{\star \star}$} & {$[0.01]^{\star \star}$} & {$[0.01]^{\star \star}$} & {$[0.01]^{\star \star}$} & {$[0.02]^{\star \star}$} \\
\hline \multirow[t]{2}{*}{ (In) power outages } & -0.13 & -0.14 & -0.15 & -0.12 & -0.29 & -0.4 \\
\hline & {$[0.00]^{\star \star}$} & {$[0.00]^{\star \star}$} & {$[0.00]^{\star \star}$} & {$[0.00]^{\star \star}$} & {$[0.01]^{\star \star}$} & {$[0.01]^{\star \star}$} \\
\hline \multirow[t]{2}{*}{ (In) distance to international port } & -0.13 & -0.13 & -0.19 & -0.18 & -0.46 & -0.53 \\
\hline & {$[0.00]^{\star \star}$} & {$[0.00]^{\star \star}$} & {$[0.00]^{\star \star}$} & {$[0.00]^{\star *}$} & {$[0.01]^{\star \star}$} & {$[0.01]^{\star *}$} \\
\hline \multirow[t]{2}{*}{ stamp duty rate } & -0.03 & -0.03 & -0.03 & -0.02 & -0.05 & -0.05 \\
\hline & {$[0.00]^{\star \star}$} & {$[0.001]^{\star \star}$} & {$[0.00]^{\star \star}$} & {$[0.001]^{\star \star}$} & {$[0.00]^{\star \star}$} & {$[0.01]^{\star \star}$} \\
\hline \multirow[t]{2}{*}{ (In) industrial credit } & 0.03 & 0.01 & 0.06 & 0.04 & 0.01 & 0 \\
\hline & {$[0.00]^{\star \star}$} & {$[0.00]^{\star \star}$} & {$[0.00]^{\star \star}$} & {$[0.00]^{\star *}$} & {$[0.00]^{\star \star}$} & {$[0.00]$} \\
\hline \multirow[t]{2}{*}{ (In) own industry concentration } & 0.12 & 0.18 & 0.18 & 0.26 & 0.33 & 0.17 \\
\hline & {$[0.002]^{\star \star}$} & {$[0.01]^{\star \star}$} & {$[0.01]^{\star \star}$} & {$[0.01]^{\star \star}$} & {$[0.01]^{\star \star}$} & {$[0.01]^{\star *}$} \\
\hline \multirow[t]{2}{*}{ (In) wages } & 0.25 & 0.22 & 0.01 & -0.21 & -0.14 & 0.31 \\
\hline & {$[0.01]^{\star \star}$} & {$[0.01]^{\star \star}$} & {$[0.01]$} & {$[0.02]^{\star *}$} & {$[0.03]^{\star \star}$} & {$[0.03]^{\star *}$} \\
\hline \multirow[t]{2}{*}{ Constant } & 1.87 & 1.8 & 6.51 & 8.18 & 5.77 & 2.89 \\
\hline & {$[0.07]^{\star \star}$} & {$[0.08]^{\star \star}$} & {$[0.10]^{\star \star}$} & {$[0.14]^{\star \star}$} & {$[0.25]^{\star \star}$} & {$[0.25]^{\star *}$} \\
\hline R-squared & 0.52 & & 0.47 & & 0.48 & \\
\hline \multirow{2}{*}{$\begin{array}{l}\text { Durbin-Wu-Hausman test for } \\
\text { endogeneity of industry concentration } \\
\text { (P-value) }\end{array}$} & 95.84 & & 80.07 & & 151.93 & \\
\hline & 0.00 & & 0.00 & & 0.00 & \\
\hline
\end{tabular}

Robust standard errors in brackets

+ significant at 10\%; * significant at 5\%; ** significant at $1 \%$

Note: Own industry concentration is endogenous; historical land revenue systems (Zamindari system) used as instrument. 


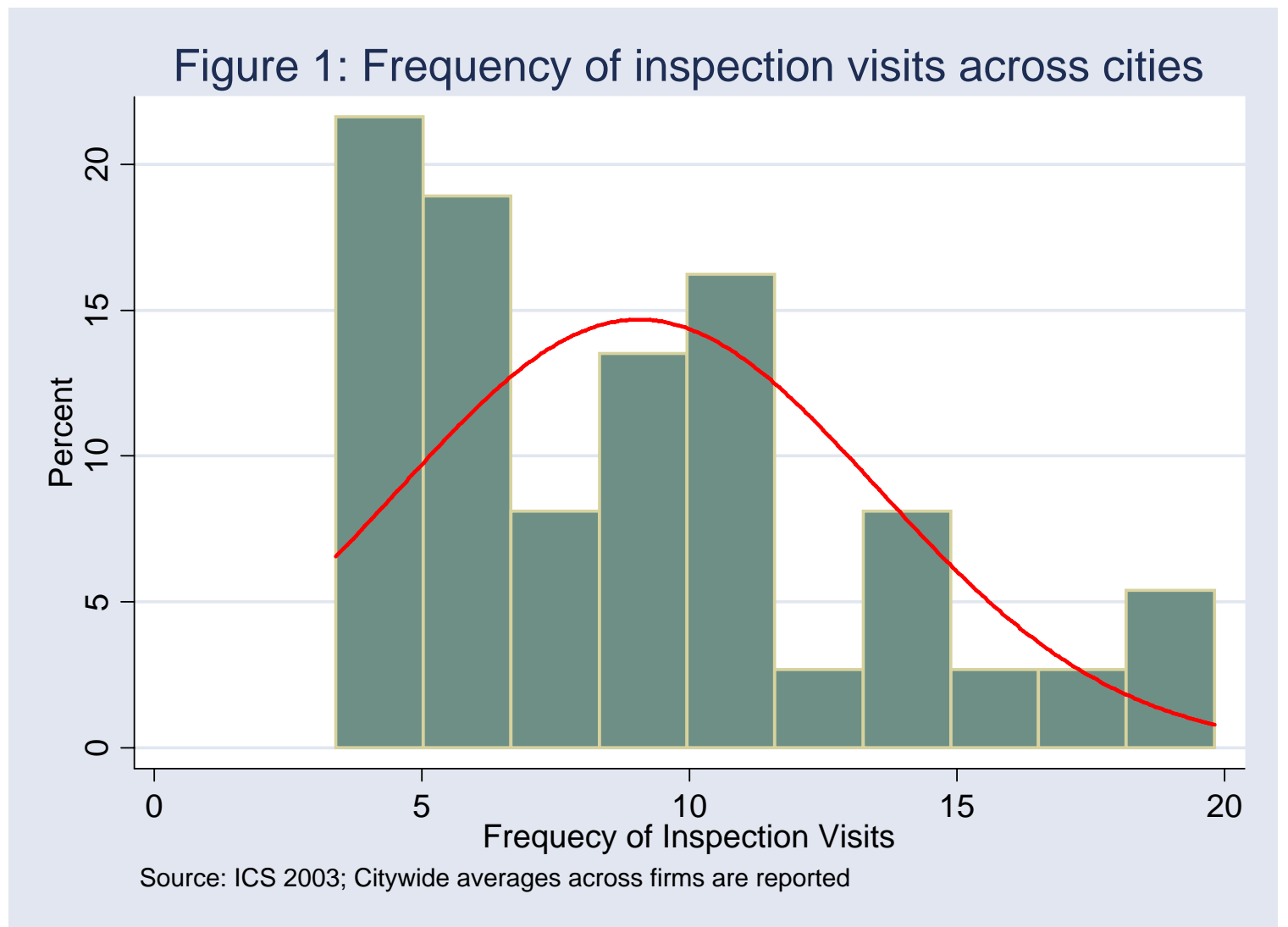


Appendix 1: Cities covered by the investment climate survey of 2003

\begin{tabular}{llll}
\hline Metropolitan cities & Large cities & & Smaller cities \\
\hline Delhi & Pune & Chandigarh & Gwalior \\
Mumbai & Surat & Cochin & Mangalore \\
Kolkata & Lucknow & Mysore & Nashik \\
Chennai & Kanpur & Vijayawanda & Nagpur \\
Bangalore & Bhopal & Guntur & Thane \\
Ahmadabad & Ludhana & Gurgaon & Jalandhar \\
Hyderabad & Indore & Panipat & Coimbatore \\
& Vadodara & Hubli-Dharwad & Hosur \\
& Faridabad & Calicut & Madurai \\
& & Palakkad & Ghaziabad \\
& & & Noida \\
& & & Howarah \\
& & & Shahjahanpur-Lakimpur \\
\hline
\end{tabular}

\section{Appendix 2: Classification of industries into broad categories}

\begin{tabular}{llll}
\hline $\begin{array}{l}\text { Resource } \\
\text { Based }\end{array}$ & $\begin{array}{l}\text { Low } \\
\text { Technology }\end{array}$ & $\begin{array}{l}\text { Medium } \\
\text { Technology }\end{array}$ & High Technology \\
\hline \hline Sugar & Garments & Electronics & Drugs \\
$\begin{array}{l}\text { Food } \\
\text { Processing }\end{array}$ & Textiles & $\begin{array}{l}\text { Electrical White } \\
\text { Goods }\end{array}$ & Pharmaceuticals \\
& $\begin{array}{lll}\text { Leather } \\
\text { Leather }\end{array}$ & Machine Tools & Chemicals \\
& $\begin{array}{l}\text { Products } \\
\text { Metals }\end{array}$ & Auto components & \\
& & & \\
\hline
\end{tabular}

